\begin{tabular}{|c|c|c|}
\hline 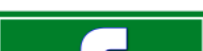 & Int.J.Curr.Microbiol.App.Sci (2021) 10(08): 278-284 & \\
\hline & $\begin{array}{l}\text { International Journal of Current Microbiology and Applied Sciences } \\
\text { ISSN: 2319-7706 Volume } 10 \text { Number } 08 \text { (2021) } \\
\text { Journal homepage: http://www.ijcmas.com }\end{array}$ & 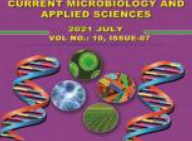 \\
\hline $\begin{array}{l}\text { EXCELLENT } \\
\text { PUBLISHERS }\end{array}$ & & \\
\hline
\end{tabular}

Original Research Article https://doi.org/10.20546/ijcmas.2021.1008.032

\title{
Invitro Antioxidant Properties of Punganur Cow Urine at Different Physiological Stages
}

\author{
C. H. Pooja ${ }^{1^{*}}$, K. Padmaja ${ }^{1}$, P. Eswara Prasad ${ }^{2}$, Punya Kumari ${ }^{3}$ and K. Jayasri ${ }^{1}$ \\ ${ }^{1}$ Department of Veterinary Biochemistry, ${ }^{2}$ Director of Research, \\ ${ }^{3}$ Department of Animal Genetics and Breeding, College of Veterinary Science, Sri \\ Venkateswara Veterinary University, Tirupati-517502, India \\ *Corresponding author
}

\section{Keywords}

Oxidative stress,

TAC, Free radical scavenging activity, Punganur cow urine

Article Info

Accepted:

15 July 2021

Available Online:

10 August 2021

\section{A B S T R A C T}

Cow plays a vital role in the socio-economic structure of rural India and cow urine is known for its medicinal values traditionally. Even though there are various reports on cow urine composition, there exist a lacunae on the antioxidant nature of Punganur cattle urine. Studies on oxidative stress and antioxidant nature of urine helps to establish the redox status and health status of Punganur cows at different physiological stages. Hence a study was carried out on thirty (30) Punganur cows (10 each) at different physiological stages viz, heifers, lactating and dry cows present at Livestock research station, Palamaner, Chittor district, Andhra Pradesh. In urine samples, oxidative stress, Total Antioxidant Capacity and free radical scavenging activity were evaluated. The results showed lower levels of MDA, higher values of TAC and free radical scavenging activities (superoxide, hydroxyl, nitric oxide and DPPH radicals)in urine of heifers which in turn reflects its more antioxidant potential. It was evident that free radical scavenging activity and reducing power were correlated with the TAC, hence single assay of TAC may be recommended to assess the antioxidant status of cow urine.

\section{Introduction}

Cow is the backbone of Indian culture and rural economy and it sustains our life, represent cattle wealth and biodiversity. Indian subcontinent has a rich genetic diversity of livestock with recognized cattle breeds. Most of these breeds are undergoing genetic degradation due to indiscriminate cross breeding and irregular mating among the breeds situated in each other's vicinity. As a result, several indigenous breeds with many desirable traits are under threat, while many others are in the process of getting replaced 
completely by certain high producing crossbred animals.

Punganur cattle is one such breed of indigenous cattle at the verge of extinction. Punganur cattle originated at Punganur, Chittoor district of Andhra Pradesh, India. Punganur cattle is the world's shortest, humped cattle with switch of the tail touching the ground. Coat color is white and light grey with a broad forehead and short horns.

This breed is known for its short stature, high milk production efficiency, high milk fat percentage and efficient reproductive characters (Ramesha, 2001). Punganur cow, the sacred Indian cow, is believed to be a mobile medical dispensary and its urine is a panacea of all diseases. The urine of Punganur cow is said to have medicinal properties such as antidiabetic activity in rats (Bhaskara Reddy et al., 2013).

Oxidative stress is one important cause of reduced fertility in dairy animals. Wate et al., (2011) proved the antioxidant activity of raw cow urine, distillate, re-distillate and its residues. Increased rate of metabolism during different physiological stages such as lactation, growth and exercise was reported to be associated with altered redox status (Celi., 2011). Rachana and Sreepada (2019), reported that raw urine of Malnad Gidda scavenged the free radicals more efficiently than its distillate, hence raw cow urine was used for evaluating the antioxidant activity.

\section{Materials and Methods}

The urine samples were collected twice during early morning hours and was filtered using sterile cotton gauze and $0.2 \mu$ filter syringe to exclude the extraneous materials like hair, dung etc then transferred into sterile amber coloured bottles and stored at $-20^{\circ} \mathrm{C}$ for further analysis.

\section{Assay of lipid peroxidation}

The concentration of MDA was measured to estimate the lipid peroxidation by the method of Niehaus and Samuelson (1968).

Urine sample $(0.5 \mathrm{ml})$ was mixed with $2 \mathrm{ml}$ of TBA-TCA-HCl reagent and tubes were boiled at $95^{\circ} \mathrm{C}$ for $15 \mathrm{~min}$. Then cooled and centrifuged at $2500 \mathrm{rpm}$ for $5 \mathrm{~min}$ and the absorbance of supernatant solution was measured at 540nm against the blank. The MDA levels in samples were calculated using 1,1,3,3-tetra methoxy propane as a standard and expressed as $\mathrm{n}$ moles of MDA/ml of urine sample.

\section{Assay of Total antioxidant capacity}

TAC of urine samples was estimated according to the method of Ciuti and Liguri (2017). One $\mathrm{ml}$ of TAC reagent was mixed with $100 \mu$ l of urine sample. The kinetic mode of absorbance for one minute at $630 \mathrm{~nm}$ with $20 \mathrm{sec}$ lag time was taken for measurement.

$\operatorname{TAC}(\mathrm{mM} \mathrm{GSH}$ equivalents $/ \mathrm{L})=\frac{\Delta \mathrm{A} \text { of sample } \times \text { Concentration of calibrator }}{\Delta \mathrm{A} \text { of calibrator }}$

Free radical scavenging activity of cow urine

\section{Hydroxyl radical scavenging Activity}

Hydroxyl radical scavenging activity was measured by the method of Rajeshwar et al., (2005). The reaction mixture was prepared by adding $0.1 \mathrm{ml}$ of EDTA, $0.1 \mathrm{ml}$ of $\mathrm{FeCl}_{3}$, $0.1 \mathrm{ml}$ of $\mathrm{H}_{2} \mathrm{O}_{2}, 0.36 \mathrm{ml}$ of deoxyribose, 0.33 $\mathrm{ml}$ of phosphate buffer and $0.1 \mathrm{ml}$ of ascorbic acid to $1 \mathrm{ml}$ of diluted urine sample $(100 \mu \mathrm{l}$ of sample added to $900 \mu \mathrm{l}$ distilled water). All the contents were mixed thoroughly and incubated at $37{ }^{\circ} \mathrm{C}$ for $1 \mathrm{~h}$. To $1 \mathrm{ml}$ of this mixture $1 \mathrm{ml}$ of TCA, $1 \mathrm{ml}$ of TBA were added and then mixed thoroughly. The control was prepared by adding the same volume of 
the above reaction mixture without urine sample. Then absorbance was measured at 532 $\mathrm{nm}$. Percentage of hydroxyl radical scavenged was calculated using the following formula.

Radical scavenged $(\%)=\left[\left(\mathrm{A}_{0}-\mathrm{A}_{1}\right) / \mathrm{A}_{0}\right] \times 100$.

where $\mathrm{A}_{0}$ is the absorbance of the control and $A_{1}$ is the absorbance of the sample.

\section{Nitric oxide radical scavenging Activity}

Nitric oxide radical scavenging activity was carried out according to Mondal et al., (2006). To $1 \mathrm{ml}$ of sodium nitroprusside solution, $1 \mathrm{ml}$ of diluted urine sample $(100 \mu \mathrm{l}$ of urine sample diluted with $900 \mu \mathrm{l}$ distilled water) was added and then incubated at $25^{\circ} \mathrm{C}$ for $2 \mathrm{~h}$ and $30 \mathrm{~min}$.

Then $1 \mathrm{ml}$ of this solution was added to $1 \mathrm{ml}$ of Griess's reagent, mixed thoroughly and absorbance was measured at $546 \mathrm{~nm}$ against the blank. The control was prepared by adding the same volume of the above reaction mixture without urine sample. Percentage of nitric oxide radical scavenged was calculated using the following formula.

Radical scavenged $(\%)=\left[\left(\mathrm{A}_{0}-\mathrm{A}_{1}\right) / \mathrm{A}_{0}\right] \times 100$.

where $\mathrm{A}_{0}$ is the absorbance of the control and $A_{1}$ is the absorbance of the sample.

\section{Superoxide anion scavenging activity}

Superoxide anion scavenging activity was measured according to the method of Gulcin et al., (2002). The reaction mixture was prepared by adding $1 \mathrm{ml}$ of NBT solution, 1 $\mathrm{ml}$ of NADH solution and $100 \mu \mathrm{l}$ of PMS solution to $100 \mu \mathrm{l}$ of urine sample $(100 \mu \mathrm{l}$ of sample dissolved in $900 \mu \mathrm{l}$ of distilled water) and incubated at $25{ }^{\circ} \mathrm{C}$ for $5 \mathrm{~min}$. The absorbance was measured at $560 \mathrm{~nm}$ against the blank. The control was prepared by adding the same volume of above reaction mixture without urine sample. Percentage of superoxide anion radical scavenged was calculated using the following formula.

Radical scavenged $(\%)=\left[\left(\mathrm{A}_{0}-\mathrm{A}_{1}\right) / \mathrm{A}_{0}\right] \times 100$

where $A_{0}$ is the absorbance of the control and $A_{1}$ is the absorbance of the sample.

\section{DPPH Free radical scavenging Activity}

The antioxidant activity through DPPH free radical scavenging system was evaluated by the method of Yang et al., (2011). The free radical scavenging activity of the urine samples were measured by using DPPH.

The control was prepared by taking the same volume of DPPH and methanol without urine sample. To $100 \mu 1$ of diluted urine samples

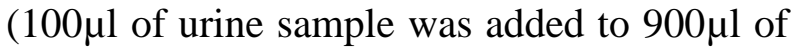
distilled water) $100 \mu 1$ of DPPH was added in a 96-well plate. The reaction mixture was kept at room temperature in dark for 20 minutes, and then absorbance was measured at $517 \mathrm{~nm}$ against the blank. Ascorbic acid was used as a standard. The percentage of DPPH radical scavenged was calculated using the following formula.

Radical scavenged $(\%)=\left[\left(\mathrm{A}_{0}-\mathrm{A}_{1}\right) / \mathrm{A}_{0}\right] \times 100$,

where $A_{0}$ is the absorbance of the control and $A_{1}$ is the absorbance of the sample.

\section{Reducing Power Assay}

Reducing power assay was done according to Makari et al., (2008).

Urine dilution was done by adding $100 \mu \mathrm{l}$ of sample to $900 \mu \mathrm{l}$ of phosphate buffer. To 100 $\mu 1$ of sample, $500 \mu \mathrm{l}$ of $1 \% \mathrm{~K}{ }_{3} \mathrm{Fe}(\mathrm{CN}){ }_{6}$ was added, mixed thoroughly and incubated at 50 ${ }^{\circ} \mathrm{C}$ for $20 \mathrm{~min}$. The reaction was terminated by adding $500 \mu \mathrm{l}$ of $10 \%$ TCA solution and then centrifuged at $3000 \mathrm{rpm}$ for $10 \mathrm{~min}$. 
The upper layer of solution was mixed with $1.5 \mathrm{ml}$ of distilled water and $300 \mu \mathrm{l}$ of $0.1 \%$ $\mathrm{FeCl}_{3}$ solution. The absorbance was measured at $700 \mathrm{~nm}$ against the blank. Ascorbic acid was used as a standard and increase in absorbance of the reaction mixture is indicator for increased reducing power.

Reducing power $(\mu \mathrm{g}$ Ascorbic acid equivalents $\mathrm{ml})=\mathrm{OD}$ of test $\times$ Concentration of standard OD of standard

\section{Results and Discussion}

Oxidative stress and In vitro antioxidant status of Punganur cow urine

In vitro antioxidant properties (TAC, hydroxyl, nitric oxide, superoxide, DPPH radicals and reducing power) were mentioned in Table 1.

In the present study, concentration of MDA was significantly higher in lactating cows compared to dry cows and heifers (Fig. 1). Whereas, TAC was significantly lower in urine of lactating cows and higher in heifers. Our results are in agreement with Omidi et al., (2017) who reported low levels of TAC and high levels of MDA in serum of lactating cows compared to dry cows. As reported by Wachter et al., (1999) a decrease in antioxidant activity as lactation progressed was probably due to the depletion of fatsoluble antioxidants by milk. As reported by Sordillo and Aitken (2009), high metabolic demand associated with lactation would be expected to increase the production of ROS which inturn may cause oxidative stress (Castillo et al., 2005; Sharma et al., 2011).

In the present study, MDA and TAC values provided an accurate reflection of the internal physiological status of the animal and suggest that decrease in TAC might have resulted in increased oxidative stress during lactation stage in Punganur cows.
Free radical scavenging activity and reducing power of Punganur cow urine

Free radical scavenging activity was high in urine of Punganur heifers followed by dry and lactating cows. Hydroxyl free radicals are the products of oxygen metabolism which induce the oxidative stress and are highly reactive towards biological molecules. In hydroxyl radical scavenging assay, the incubation of ferric - EDTA with $\mathrm{H}_{2} \mathrm{O}_{2}$ and ascorbic acid at $\mathrm{pH} 7.4$ generated hydroxyl radicals which were distinguished by their ability to degrade 2-deoxy-D-ribose into fragments, on heating with TBA at low $\mathrm{pH}$ resulting in a pink chromogen (Lobo et al., 2010). The antioxidants present in cow urine removed the hydroxyl radicals and prevented the degradation of 2-deoxy-D-ribose.

Sodium nitroprusside (SNP) acts as the main source of NO generation, which reacts with oxygen and forms nitrite. Significantly high NO radical scavenging activity was observed in urine of heifers compared to dry and lactating cows. Cow urine inhibit the formation of nitrite by directly competing with oxygen, thereby showed its potential NO scavenging ability as reported by Archana and Vijayalakshmi (2018). The NO and hydroxyl radical scavenging activity of Punganur cow urine was more or less similar to that of raw urine of Malnad Gidda cows (Rachana and Sreepada, 2019).

Superoxide anion scavenging activity was found to be low in urine of lactating cows compared to dry cows and heifers. Superoxide anions produced by some metabolic reactions in the body are not directly involved in lipid peroxidation, but they are the precursor molecules for hydroxyl free radical generation. The superoxide anion scavenging activity of urine in Punganur cows was corroborated with findings of Rachana and Sreepada (2019) in Malnad Gidda. 
Table.1 Invitro Antioxidant status of Punganur Cow urine

\begin{tabular}{|c|c|c|c|}
\hline Parameter & Heifers & Lactating & \multicolumn{1}{c|}{ Dry } \\
\hline TAC(mMoles/L) & $2.44^{\mathrm{c}} \pm 0.11$ & $1.05^{\mathrm{a}} \pm 0.03$ & $1.46^{\mathrm{b}} \pm 0.02$ \\
\hline Hydroxyl radical (\%) & $66.04^{\mathrm{c}} \pm 0.58$ & $49.27^{\mathrm{a}} \pm 1.63$ & $53.42^{\mathrm{b}} \pm 0.62$ \\
\hline Nitric oxide radical (\%) & $42.64^{\mathrm{b}} \pm 1.28$ & $36.08^{\mathrm{a}} \pm 0.78$ & $37.46^{\mathrm{a}} \pm 0.78$ \\
\hline Superoxide radical (\%) & $89.76^{\mathrm{c}} \pm 0.85$ & $73.82^{\mathrm{a}} \pm 1.11$ & $82.61^{\mathrm{b}} \pm 1.19$ \\
\hline DPPH radical (\%) & $52.49^{\mathrm{c}} \pm 1.01$ & $37.47^{\mathrm{a}} \pm 1.23$ & $44.08^{\mathrm{b}} \pm 0.91$ \\
\hline $\begin{array}{c}\text { Reducing power assay } \\
(\boldsymbol{\mu g} / \mathbf{m l})\end{array}$ & $78.72^{\mathrm{b}} \pm 0.19$ & $77.06^{\mathrm{a}} \pm 0.25$ & $77.19^{\mathrm{a}} \pm 0.32$ \\
\hline
\end{tabular}

Values are mean \pm SE $(n=30)$

Means with different superscripts in each row differ significantly $(\mathrm{p}<0.05)$

Fig.1 Mean values of MDA in urine samples of Punganur cow.

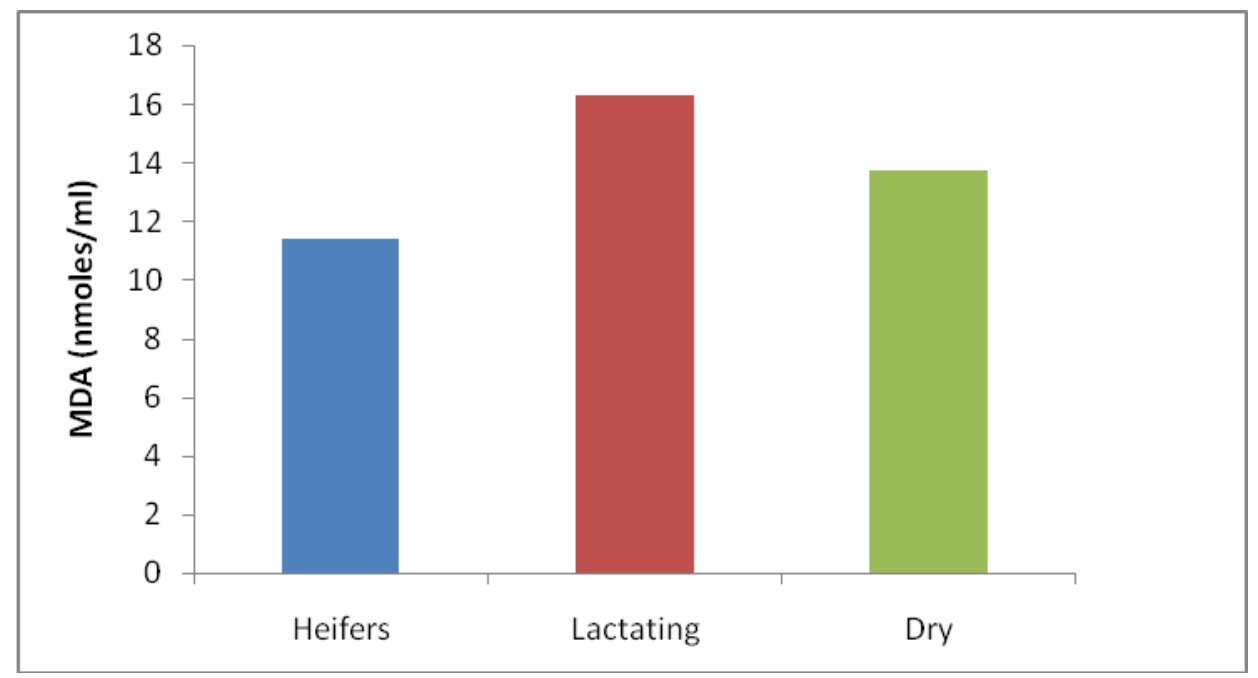

DPPH free radical inhibition ability was significantly higher in urine of heifers compared to lactating and dry cows. The absorbance of DPPH is decreased as it gains electrons in the presence of antioxidant. As reported by Bajpai et al., (2013), the bleaching of DPPH absorption reflects the proton donating activity and thereby free radical inhibition activity of cow urine. Similar DPPH radical scavenging activity of cow urine was reported by Joshi et al., (2019) in different altitudinal and climatic regions of Nepal.

Potent reducing capability and antioxidant potential was observed in Punganur cow urine and it was found to be high in heifers compared to lactating and dry cows. As reported earlier, the reducing power of indigenous cow urine was due to its electron donating ability reflecting the potential antioxidant activity of cow urine (Wate $e t$ al., 2011; Benslama and Harrar, 2016).

Low levels of free radical (nitric oxide, hydroxyl, superoxide and DPPH) scavenging activity and reducing power observed in urine of lactating cows may be due to the fact that the most critical time in cows appears to be the beginning of the lactation, where the negative energy balance favours lipid mobilization and gluconeogenesis, in terms of oxidative balance which produces excess free 
radicals (Castillo et al., 2006). Increased TAC was observed in heifer urine compared to that of dry and lactating Punganur cows. Decreased MDA levels in heifers may be due to its potential antioxidant activities compared to dry and lactating Punganur cows. Antioxidant property of cow urine may provide potential therapeutic intervention against oxidative threats, both in health and disease. The results suggests that the antioxidant action is attributed to the free radical scavenging activity of the cows urine components.

\section{References}

Archana, I., and Vijayalakshmi, K. 2018. Antioxidant potential of phloroglucinol; an in-vitro approach. International Journal of Pharmaceutical Sciences and Research, 9(7): 2947-2951.

Bajpai, V. K., Sharma, A., Kim, S. H., Kim, Y., Kim, J. J., and Baek, K. H. 2013. Microwave-assisted seed essential oil of Eleutherococcussenticosus and its antioxidant and free radicalscavenging activities. Journal of Food Biochemistry, 37(1):119-127.

Benslama, A., and Harrar, A. 2016. Free radicals scavenging activity and reducing power of two Algerian Sahara medicinal plants extracts. International Journal of Herbal Medicine, 4(6):158-161.

Bhaskara Reddy. M, Vijaya \& Akshintala, Karthik and Sasikala, P. 2013. Protective role of Punganur cow urine on streptozotocin induced diabetes in rats. International Research Journal of Pharmacy. 4:164-167.

Castillo, C., Hernandez, J., Bravo, A., LopezAlonso, M., Pereira, V., and Benedito, J. L. 2005. Oxidative status during late pregnancy and early lactation in dairy cows. The Veterinary Journal, 169(2),
286-292.

Castillo, C., Hernandez, J., Valverde, I., Pereira, V., Sotillo, J., Alonso, M. L., and Benedito, J. L. 2006. Plasma malonaldehyde (MDA) and total antioxidant status (TAS) during lactation in dairy cows. Research in Veterinary Science, 80(2):133-139.

Celi, P., 2011. Biomarkers of oxidative stress in ruminant medicine. Immunopharmacology and Immunotoxicology, 33(2): 233-240.

Ciuti, R., and Liguri, G. 2017. A novel assay for measuring total antioxidant capacity in whole blood and other biological samples. Journal of Biomedical Science and Engineering, 10(02):60-76

Gülçin, İ., Oktay, M., Küfrevioğlu, Ö. İ., and Aslan, A. 2002. Determination of antioxidant activity of lichen Cetrariais landica (L) Ach. Journal of Ethnopharmacology, 79(3):325-329.

Joshi, D. R., Aryal, P., Chaudhary, M. K., B K, P. K., Yadav, S. P., Rawal, P., Adhikari, N., and Bhandari, R. 2019. Study of in-vitro Antioxidant and Antibacterial Activity of Cow Urine from Different Altitudinal and Climatic Region of Nepal. Microbiology Research Journal International, 1-8.

Lobo, V., Patil, A., Phatak, A., and Chandra, N. 2010. Free radicals, antioxidants and functional foods: Impact on human health. Pharmacognosy Reviews, 4(8): 118 .

Makari, H. K.,Haraprasad, N., Patil, H. S., and Ravikumar, S. 2008. In vitro antioxidant activity of the hexane and methanolic extracts of Cordiawallichii and Celastruspaniculata. Internet Journal of Aesthetic and Antiaging Medicine, 1:1-10.

Mondal, S. K., Chakraborty, G., Gupta, M., and Mazumder, U. K. 2006. In vitro 
antioxidant activity of DiospyrosmalabaricaKostel bark. Indian Journal of Experimental Biology, 44:39-44

Niehaus, W. G., and Samuelson, B. 1968. Formation of malondialdehyde from and glucose 6-phosphate dehydrogenase from fermenting yeast and phospholipids arachidonate during microsomal lipid peroxidation. European Journal of Biochemistry, 6:126-30.

Omidi, A., Fathi, M. H., and Parker, M. 2017. Alterations of antioxidant status markers in dairy cows during lactation and in the dry period. Journal of Dairy Research, 84(1):49-53.

Rachana B and Sreepada K S 2019. Antioxidant and Anti-inflammatory activities of cow urine from MalnadGidda- An indigenous breed. International Journal of Pharmaceutical Sciences and Research, 10(2):612-618.

Rajeshwar, Y., Kumar, G. S., Gupta, M., and Mazumder, U. K. 2005. Studies on in vitro antioxidant activities of methanol extract of Mucunapruriens (Fabaceae) seeds. European Bulletin on Drug Research, 13(1):31-39.

Ramesha, K. P. 2001. Commissioned paper in the thematic working group on
Domesticated Bio-Diversity, National Biodiversity Strategy and Action Plan, Ministry of Environment and Forestry, Government of India.

Sharma, N., Singh, N. K., Singh, O. P., Pandey, V., and Verma, P. K. 2011. Oxidative stress and antioxidant status during transition period in dairy cows. Asian-Australasian Journal of Animal Sciences, 24(4):479-484.

Sordillo, L. M., and Aitken, S. L. 2009. Impact of oxidative stress on the health and immune function of dairy cattle. Veterinary Immunology and Immunopathology, 128(1-3):104-109.

Wachter, C. M., McDaniel, B. T., Whitlow, L. W., and Pettyjohn, S. 1999. Genetics of antioxidant activity in Holsteins and Jerseys: associations with various traits. Journal of Dairy Science, 82(1):31.

Wate, S. P., Dhanjode, D. P., Duragkar, N. J., and Tajne, M. R. 2011. Antioxidant potential of cow urine and its fractions: A comparative study. International Journal of Universal Pharmacy and Life Sciences, 1(1):146-54.

Yang, H., Dong, Y., Du, H., Shi, H., Peng, Y., and $\mathrm{Li}, \mathrm{X}$. 2011. Antioxidant compounds from propolis collected in Anhui, China. Molecules, 16(4): 34443455 .

\section{How to cite this article:}

Pooja, C. H., K. Padmaja, P. Eswara Prasad, Punya Kumari and Jayasri, K. 2021. In vitro Antioxidant Properties of Punganur Cow Urine at Different Physiological Stages. Int.J.Curr.Microbiol.App.Sci. 10(08): 278-284. doi: https://doi.org/10.20546/ijcmas.2021.1008.032 